\title{
General notes
}

\section{EDITORIAL NOTE}

From the beginning of 1981 , in order to save both time and expense, the Publishers of this Journal will be omitting galley proofs and will print page proofs only.

So that I may have the original manuscripts to check against the page proofs, the manuscripts will be sent to me and not to authors.

Contributors are advised, therefore, to retain copies of their manuscripts in future when they submit articles to the Journal.

\section{JOHN BALLANTYNE}

\section{Editor}

\section{REHABILITATION OF HEARING IMPAIRED ADULTS A COMPREHENSIVE APPROACH}

SUITABLE FOR MEDICAL PRACTITIONERS, AUDIOLOGICAL SCIENTISTS, HEARING THERAPISTS

AND THOSE IN RELATED FIELDS

\section{7, 28 AND 29 MAY, 1981}

THE lectures and demonstrations will be given by the staff of the Department of Auditory Rehabilitation of the Royal National Throat, Nose and Ear Hospital and a number of visiting lecturers including Professor David Goldstein of Purdue University, USA.

The curriculum will be based on a comprehensive model for the process of audiological rehabilitation recently developed within this Department.

This model aims to integrate the evaluation and remediation processes of rehabilitation. It emphasizes the importance of non-instrumental factors, particularly the patient's attitude. The rehabilitation approach based on this model involves a combination of non-instrumental and instrumental factors to provide the best rehabilitation for each individual patient. The details and value of such an approach will be illustrated by case studies and video recorded presentations. The aim of the course is to teach those attending how to use the model to improve their daily practice.

FEE: $\mathfrak{E} 75$ (including morning coffee, lunch and tea). 


\title{
TEMPORAL BONE SURGICAL DISSECTION COURSE
}

\author{
EAR RESEARCH INSTITUTE
}

In Cooperation With

University of Southern California School of Medicine

TWO WEEKS EACH

March, April, October, November 1981 AND 1982

Participants spend four hours daily in the dissection laboratory and four hours observing live telecasts of surgery. The course includes early evening lectures and films, and demonstration and practice of the multiple approaches to the structures of the Temporal Bone used by members of the Otologic Medical Group, Inc.

Each course is limited to 24 board certified or board eligible otolaryngologists and residents.

Tuition (U.S. Currency):

Physicians: $\$ 1,500.00$

Residents: $\$ 1,200.00$

(With letter from Chief of Service)

CME Credit: 100 Hours

For further information: Antonio De La Cruz, M.D., Director, Temporal Bone

Surgical Dissection Course, Ear Research Institute, 256 South Lake Street, Los Angeles, CA 90057.

\section{THE TWJ FOUNDATION}

THE Trustees of the TWJ Foundation wish to announce that the 1981 TWJ Otological Research Fellowship at the Coleman Institute, San Francisco, has been awarded to Mr. Roger Gray, F.R.C.S., Senior Registrar in Otolaryngology at the Royal Free Hospital and the Royal Surrey County Hospital, Guildford.

At the invitation of the University of Michigan a TWJ Otological Clinical and Research Fellowship has been established at the Ear, Nose and Throat Department at Ann Arbor. The first such Fellowship for six months in 1981 has been awarded to Mr. Martin Bailey, F.R.C.S., Senior Registrar in Otolaryngology at the Royal National Throat, Nose and Ear Hospital, London and the Royal Sussex County Hospital, Brighton. 


\title{
FIRST INTERNATIONAL SYMPOSIUM ON MINIMAL INVASIVE CANCER
}

\author{
ORGANIZED BY \\ The University Clinic of Obstetrics and Gynecology \\ GraZ
}

Graz, Kongreßhaus, 1-4 July 1981

MaIN Topics:

Cervix, Vulva, Endometrium, Breast, Esophagus, Stomach, Large intestine, Lung, Thyroid, Urinary bladder, Prostate, Larynx, Oral cavity, Skin, Other organs.

Congress Language: English

Organization: $\quad$ President-Professor E. Burghardt, M.D. Secretary General-E. Holzer, M.D.

Secretariat: Interconvention

P.O. Box 105

A-1014 Vienna

Tel.: (0222) 576288

\section{INTERNATIONAL RHINOLOGIC SOCIETY}

\section{HiLTon Hotel, BuDAPEST}

\section{6-19 JUNE 1981}

A postgraduate course in functional surgery of the septum and external nasal pyramid will be given prior to the XII World Congress of ORL.

The course will include lectures, video-tape operative demonstrations and discussions in smaller groups. There will be an international panel of guest lecturers. The course will be given mostly in English, with discussion groups in French, German, Japanese and Eastern European languages.

Registration limited to 150 .

Course fee: U.S. \$300-before 1 April 1981; after 1 April, U.S. \$400. Limited scholarships are available. The registration fee includes the course book, buffet receptions at the American Embassy, five coffee breaks, two luncheons and course banquet on the final night (Friday, 19 June 1981).

Registration and further information: Professor Dr. H. Masing,

Waldstraße 1,

D-8520 Erlangen,

West Germany. 


\section{BELGIAN ENT SOCIETY}

\section{InTERNATIONAL Symposium ON Otospongiosis}

\section{JUNE 1981}

THE Belgian ENT Society is organizing an international symposium on Otospongiosis on 13 June 1981.

The medical and surgical aspects of this subject will be discussed, with the collaboration of Professors Friedmann, Marquet, Portmann and Shambaugh, under the Presidency of Dr. Van Fraeyenhoven.

For further information, please write to: Dr. Huberty,

13 St. Janstraat, B 8000 Brugg,

Bruges,

Belgium.

THE JAMES YEARSLEY MEMORIAL LECTURE 1981

\section{MARCh 1981}

THE James Yearsley Memorial Lecture for 1981 will be given at the Royal Society of Medicine by Professor Dietrich Plester, of Tübingen, whose subject will be 'When not to operate for conductive hearing loss?'

\section{ELEVENTH GLASGOW TEMPORAL BONE COURSE}

A three-day practical course in temporal bone dissection will be held in Glasgow over the weekend 24, 25 and 26 April 1981 . The course will comprise dissection of the temporal bone integrated with lectures on the indication, techniques and results of otological surgery and on the growth and histological anatomy of the temporal bone. This will be supplemented by televised surgical demonstrations.

The course is primarily designed for those in the Registrar and Senior Registrar Grades and is approved by the Postgraduate Medical Education Committee and is therefore approved for study leave and expenses.

Further details and application forms can be obtained from:

Mr. G. G. Browning,

Glasgow University Department of Otorhinolaryngology,

Royal Infirmary,

Glasgow G4 OSF. 
